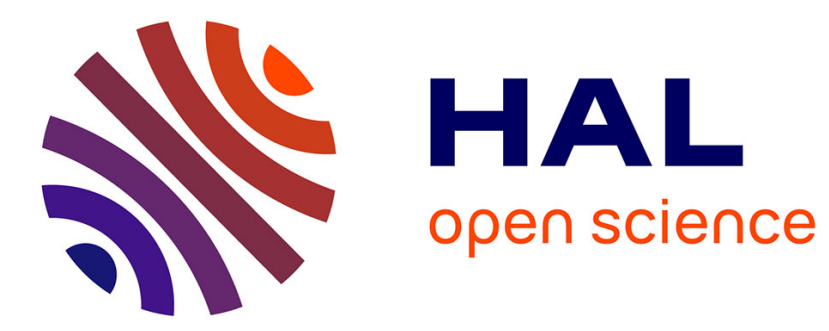

\title{
New Markers for Adult-Onset Still's Disease
}

Stéphane Mitrovic, Bruno Fautrel

\section{- To cite this version:}

Stéphane Mitrovic, Bruno Fautrel. New Markers for Adult-Onset Still's Disease. Joint Bone Spine, 2017, 10.1016/j.jbspin.2017.05.011 . hal-01533477

\section{HAL Id: hal-01533477 https: / hal.sorbonne-universite.fr/hal-01533477}

Submitted on 6 Jun 2017

HAL is a multi-disciplinary open access archive for the deposit and dissemination of scientific research documents, whether they are published or not. The documents may come from teaching and research institutions in France or abroad, or from public or private research centers.
L'archive ouverte pluridisciplinaire HAL, est destinée au dépôt et à la diffusion de documents scientifiques de niveau recherche, publiés ou non, émanant des établissements d'enseignement et de recherche français ou étrangers, des laboratoires publics ou privés. 


\title{
New Markers for Adult-Onset Still's Disease
}

\author{
Stéphane Mitrovic ${ }^{1,2}$, Bruno Fautrel ${ }^{1,2}$ \\ 1UPMC University Paris 06, institut Pierre-Louis d'épidémiologie et de santé publique, GRC- \\ UPMC 08 (EEMOIS), Sorbonne universités, 75005 Paris, France \\ ${ }^{2}$ Department of Rheumatology, Pitié-Salpêtrière Hospital, AP-HP, 75013 Paris, France
}

Corresponding author: $\operatorname{Pr}$ Bruno Fautrel, Hôpital Pitié-Salpétrière, Service de Rhumatologie, 47-83, boulevard de l'Hôpital - 75013 Paris France. Mail: bruno.fautrel@aphp.fr Tel: +33142177620 Fax: +33142177955 


\begin{abstract}
:
Adult-onset Still's disease (AOSD) is a rare systemic auto-inflammatory disorder (SAID). Although the pathogenesis of the disease is complex and far from being fully understood, recent progresses in pathophysiological knowledge have paved the way to new diagnostic approaches. Indeed, AOSD diagnosis can be a real challenge, owing to its infrequency, and to the lack of specificity of the principal clinical features (high fever, arthralgia or arthritis, skin rash) and laboratory findings (elevated acute phase reactants, hyperleukocytosis $\geq 10,000$ cells $/ \mathrm{mm}^{3}$ with neutrophils $\geq 80 \%$ ). None of these manifestations is disease-specific, so clinicians must first rule out neoplastic, infectious or inflammatory conditions. Besides these diagnostic difficulties, several other challenges remain. AOSD is very heterogeneous in terms of clinical presentation, evolution and severity. Thus, new biomarkers are required to assess: (i) disease activity; (ii) disease severity (through the identification of patients at risk of severe organ failure, and eventually of life-threatening complications, such as reactive haemophagocytic lymphohistiocytosis); (iii) disease evolution (which can be monophasic, relapsing, or progressive, with either systemic inflammation or chronic erosive arthritis); (iv) and treatment efficacy. The identification of new markers can only be done through a better understanding of the pathogenesis of the disease. After a short focus on the current AOSD pathophysiological knowledge, this article reviews the main biomarkers that have been proposed in the literature over the last few years.
\end{abstract}

Key words: Adult-onset Still's disease; biomarkers; ferritin; Interleukin-18; S100 proteins; calprotectin 


\section{Introduction: a diagnostic challenge}

Adult-onset Still's disease (AOSD) is a rare systemic auto-inflammatory disorder (SAID) that was first described in the early 1970's (1), about a century after the description of its childhood counterpart, the systemic form of juvenile inflammatory arthritis (sJIA). AOSD's incidence is estimated at 0.16 to 0.4 per 100,000 persons according to the countries $(2,3)$, and reported prevalence rates range from 1 to 34 cases per 1 million persons in the Japanese and the European populations (3). In most patients, AOSD is characterized by four cardinal symptoms: spiking fever, an evanescent salmon-pink maculopapular rash, arthralgia or arthritis and a white-blood-cell count (WBC) $\geq 10,000 / \mathrm{mm}^{3}$, mainly neutrophilic polymorphonuclear cells (PMNs) (2). Several other clinical and laboratory findings may occur $(2,3)$ [Appendix A, Table S1; See the supplementary material associated with this article online]. Elevated erythrocyte sedimentation rate (ESR) and C-reactive protein (CRP) levels are common (90 to $100 \%$ ). Increased serum ferritinaemia with glycosylated fraction $\leq 20 \%$ appear one of the most suggestive laboratory findings (2).

AOSD management offers several challenges. First, diagnosis of AOSD is difficult, due to infrequency of the condition and because none of the clinical and biological features is disease specific. Hence, clinicians must first rule out neoplastic, infectious or inflammatory conditions $(2,4)$ (Table 1). Diagnostic and therapeutic wavering is common; in one series of patients presenting with fever of unknown origin, $90 \%$ of those eventually diagnosed with AOSD also received antibiotics (5). There are often delays in diagnosis: a recent retrospective series of 57 patients found a mean diagnosis delay of 4 months (6). Yet, it has been shown that an early diagnosis may improve the prognosis $(6,7)$. Several sets of classification criteria have been proposed for research and may facilitate diagnosis $(4,8)$ (Table 2). AOSD is heterogeneous in terms of clinical presentation, evolution and severity, suggesting different pathogenic mechanisms (2,3). Different phenotypes have been suggested, ranging from very explosive systemic forms to more chronic articular subtypes (9-11). Most of the patients have a favourable course, while some develop life-threatening complications, such as reactive 
haemophagocytic lymphohistiocytosis (RHL). AOSD prognosis has been dramatically improved by biological therapies, although some patients may be refractory to treatment (7).

Hence, there is a real need for identifying new biomarkers for AOSD (12), which can only be done through a better understanding of the complex pathogenesis of the disease. This article reviews the main biomarkers that have been proposed in the literature in the last few years.

\section{Pathogenesis: what is already known so far}

The mechanisms underlying AOSD are not completely understood $(2,3,9,10)$. AOSD shares with autoinflammatory diseases several features: clinical manifestations (fever, skin involvements, serositis and arthritis), clinical response to interleukine (IL)-blocking strategies (especially IL-1 $\beta$ ), and above all, the absence of autoantibodies and/or auto-antigen specific T-Cells (which make the hypothesis of an autoimmune disorder in AOSD very unlikely) $(3,10)$. However, while most autoinflammatory diseases are hereditary and due to mutations in a single gene, AOSD does not cluster in families, ethnic groups or geographic areas $(2,3,13,14)$. A possible favourable genetic background has been suggested, but no consistent results have been obtained from association studies and human leukocyte antigen (HLA) gene loci $(2,3)$.

The levels of most proinflammatory cytokines, such as IL-1 $\beta$, IL-6, IL-18, tumour necrosis factor (TNF)- $\alpha$, and interferon (IFN)- $\gamma$, have been found elevated during AOSD and are thought to play a pivotal role, along with innate immunity $(3,10)$ (Figure 1). Dangers signals (pathogen-associated or damage-associated molecular patterns (PAMPS or DAMPS)) set fire, mainly into macrophages, to a dysregulated NLRP3 inflammasome, which triggers the activation, maturation and secretion of IL-1 $\beta$ and IL-18. This latter induces IFN- $\gamma$ production by $\mathrm{T}$ lymphocytes and natural killer (NK) cells, and promotes Th-1 polarization of CD4-lymphocytes and cell-mediated immunity $(3,9)$.

The disease is also strongly associated with the RHL (previously called macrophageactivation syndrome), and many data argue for a shared pathogenesis and a continuum between these two entities $(10,15)$. Similarly, whether AOSD and sJIA are the same disease remains controversial: despite many similarities, substantial differences, including various courses of the disease and different therapeutic responses, have been reported (9). These differences, as well as AOSD's great heterogeneity, may account for distinct underlying pathogenic mechanisms (9). 


\section{Expected characteristics of biomarkers in AOSD}

Two subsets of markers have been reported: while leukocytosis, elevated ESR or CRP are non-specific markers of inflammation, standing as a consequence of the pathogenic process, and therefore called "proxy" (or "descriptive"), "mechanistic" markers are directly involved in pathogenic mechanism (16). Thus, measurement of a "mechanistic" biomarker can quantify a pathologic process, through the establishment of thresholds (17).

A useful biomarker for AOSD should respond to the SMART criteria, and must be Sensitive and Specific, Measurable (with a high degree of precision), Available and Affordable, Responsive and Reproducible in a Timely fashion (16).

Proxy or mechanistic biomarkers are needed in different clinical contexts (Figure 2), and should satisfy at least one (or more) of the following goals:

\subsection{Diagnosis}

\subsubsection{AOSD diagnosis}

In accordance with the diagnostic challenges exposed in the introduction and the benefits on prognosis of an early diagnosis, this supposes to identify highly sensitive and specific biomarkers, in order to rule out the multiple differential diagnoses and thus avoid inappropriate therapy (e.g. antibiotics).

\subsubsection{Disease evolution}

Historically, the clinical course of AOSD has been distinguished in three different patterns, described on the basis of the evolution of symptoms over time: monocyclic, polycyclic and chronic evolution (Figure 3) (2).

In light of the new pieces of evidence about AOSD pathogenesis and treatment, this historic classification seems quite outdated. Hence, many authors have now adopted a new dichotomous classification, distinguishing two AOSD subtypes according to dominant clinical evolution (Figure 3): a systemic subtype, including patients with systemic features (such as high fever and skin rash), more at risk to develop life-threatening complications (such as multi-organ involvement and RHL), and a subtype where patients have predominant articular involvement $(9,10,12,18)$. Predictive factors for the evolution towards each subset have been identified: high fever $\left(>39^{\circ} \mathrm{C}\right)$, hepatitis, thrombocytopenia, elevated CRP and 
hyperferritinemia seem associated with a systemic subset, while female gender, proximal arthritis at disease onset and steroid dependence are predictive of a chronic articular evolution $(9-12,18,19)$.

\subsection{Disease activity assessment and identification of flares}

Pouchot et al. described in 199112 items comprising the main signs and symptoms of disease that may reflect its activity (20). A total score ranging from 0 to 12 can be calculated assigning 1 point to each following item: fever, evanescent rash, pleuritis, pneumonia, pericarditis, hepatomegaly or abnormal liver function tests, splenomegaly, lymphadenopathy, WBC $>15,000 / \mathrm{mm}^{3}$, sore throat, myalgia and abdominal pain. This score was later on improved by Rau et al. who replaced "splenomegaly" and "abdominal pain" with "ferritin serum levels $\geq 3000 \mu \mathrm{g} / \mathrm{L}$ " and "arthritis" (21). Recently, a new score, the Auto-Inflammatory Diseases Activity Index (AIDAI), has been validated for the assessment of disease activity in the four major hereditary recurrent fever syndromes (22). This score seems particularly interesting, but has not been yet evaluated in AOSD.

Considered the potential polycyclic evolution, it also appears necessary to identify markers able to predict a potential flare (Figure 2).

\subsection{Severity assessment}

Although AOSD course is often favourable, in some rare cases life-threatening complications may occur $(3,6)$ (Appendix A, Table S1). Some unfavourable prognostic factors have been suggested, and should make the clinicians aware of a possible negative evolution, as such cases are more prone to become refractory to treatment over the course of disease: rash, polyarthtitis, root joint arthritis (hips and shoulders), pleuritis, interstitial pneumonia, elevated ferritin levels, and failure of fever to subside after 3 days of systemic corticosteroid treatment $(6,23)$. Recently, a retrospective cohort study suggested that Pouchot's "systemic score" could predict a poor outcome in AOSD: a score $\geq 7$ and the presence of any complications (RHL, kidney failure or myocarditis) at diagnosis are associated with mortality (24).

The most feared life-threatening complication, with a reported mortality rate ranging from 10 to $22 \%$, is RHL (23). It should be highly suspected in case of high fever, lymphadenopathy, hepatosplenomegaly, pancytopenia, high serum levels of ferritin, triglycerides and liver enzymes but with normal ESR $(2,3)$. However, it is difficult to define 
strong prognostic factors in AOSD on the basis of retrospective studies that identified heterogeneous prognostic criteria $(3,6)$.

\subsection{Prediction of the therapeutic response and treatment monitoring}

Identifying different subsets of the disease could have an impact on patient management, as systemic and chronic articular subtypes seem to display different responses to treatment $(3,7,9,10,12)$. While the systemic patterns are more prone to respond to IL-1 $\beta$ antagonists (IL-1Ra), these latter seem less effective on articular features $(3,25)$. Neutralizing IL-6 with tocilizumab leads to both systemic and articular improvement $(3,9)$.

"Dynamic" disease activity biomarkers can also facilitate prediction of the ultimate clinical outcome by reporting early changes in disease-associated biological processes $(16,17)$. Results of dynamic biomarker profiling could prompt the clinician to initiate or intensify therapy in the setting of highly active disease or of an "apparent-only" relapse (Figure 2); conversely, to withdraw a specific treatment in the setting of an insufficient therapeutic response $(16,17)$.

\section{Up-to date on AOSD biomarkers}

In the past years, many efforts have been made in order to identify serological biomarkers for AOSD. The most relevant identified so far are summarised in Table 3.

\subsection{CRP and Serum amyloid A protein (SAA)}

CRP and SAA are both proxy, non-specific biomarkers that are elevated in any inflammatory condition. CRP is not discriminatory for AOSD diagnosis, but can be useful for assessing disease activity and monitoring treatment.

To our knowledge, no recent publications have explored whether SAA could be a diagnostic or prognostic biomarker. However, SAA is correlated with disease activity, and should be regularly measured in some polycyclic or chronic patterns, as uncontrolled inflammatory conditions can lead to tissue deposition responsible for amyloid A amyloidosis.

\subsection{Ferritin and glycosylated ferritin}

A high level of serum ferritin has frequently been considered one of the key diagnostic tools for many years $(2,26)$, as serum ferritin levels during AOSD are higher than in several 
other autoimmune, inflammatory, infectious or neoplastic diseases (26-28). Classically, a threshold of five times the normal value (i.e $1000 \mu \mathrm{g} / \mathrm{L}$ ) is thought to be suggestive of AOSD, with a sensitivity of $40.8 \%$ and a specificity of $80 \%$ (28). However, several studies showed that hyperferritinaemia has poor positive predictive value in isolation without a suggestive context, whatever the threshold used $(28,29)$. Serum levels of ferritin correlate not only with activity, but also with severity, independently from the pattern considered $(2,3,12)$. However, the meaning of serum ferritin levels in course prediction has still to be clarified. While Ichida et al. showed that high levels of ferritin are associated with systemic subsets (18), Colina et $a l$. found a stronger association of ferritin with the articular form of disease, demonstrating that persistence of high ferritin levels after adequate treatment may be a predictor of chronic articular course (30).

Hence, ferritin is a biomarker useful for diagnosis, disease activity assessment, prognosis, and treatment monitoring (Table 3). It is usually described as proxy, as high serum levels are an indicator of macrophage activation. However, several authors suggested that ferritin could be a mechanistic biomarker, because it may play a pro-inflammatory role by contributing to the cytokine storm (31), although this hypothesis still needs to be documented.

Besides total ferritin level, the diagnostic interest of the glycosylated ferritin (GF, a specific form of ferritin) has been suggested to be the most promising index to date $(2,28,32)$. The GF normally represents more than half the total ferritin level. In inflammatory conditions, the rate of the GF decreases and usually ranges between 20 and $50 \%$; this decrease has been related to the saturation of glycosylation mechanisms due to hyperferritinaemia, although it is not fully understood (2). However, during AOSD, the GF is quite low, $\leq 20 \%$, which suggests a more specific phenomenon. More extensive data revealed the sensitivity and specificity of $\mathrm{GF} \leq$ for AOSD diagnosis as $79.5 \%$ and $66.4 \%$, respectively (28). The combination of both hyperferritinaemia and GF $\leq 20 \%$ yielded a sensitivity and specificity of $70.5 \%$ and $83.2 \%$, respectively. Such specificity increases to $92.9 \%$ if combined with ferritin levels fivefolds above normal (28). Of note, although the serum ferritin level fluctuates according to systemic inflammation and may hence be useful as a marker of disease activity $(2,3)$, Vignes $e t$ al. showed in a study of 14 patients that GF remains low several weeks to several months after disease remission (33). However, this could not be confirmed (6). As mentioned previously, a low level of GF is not completely specific of AOSD and is observed in other inflammatory processes, such as severe systemic infections (e.g. bacterial sepsis or viral hepatitis) (28). Moreover, the GF is usually low, i.e $\leq 20 \%$, in haemophaogytic syndromes, regardless of whether their cause is infectious, neoplastic or inflammatory (2). 
Hence, GF can be considered as a (possibly mechanistic) interesting biomarker for

\subsection{Cytokines}

Except for IL-18, the cytokine profile has a limited use in clinical practice for differential diagnosis (21).

\subsection{1. $I L-18$}

The most interesting cytokine may be IL-18, whose serum levels are particularly high in AOSD (34), when compared to other inflammatory conditions such as rheumatoid arthritis (RA), polymyalgia rheumatica and sepsis (34-36). Priori et al. determined that a cut-off of $148.9 \mathrm{pg} / \mathrm{mL}$ could distinguish active AOSD from sepsis with a sensitivity of $88 \%$ and a specificity of 78\% (37), while Kim et al. found a higher sensitivity and specificity $(91.7 \%$ and 99.1\% respectively) for AOSD diagnosis with a cut-off value of $366.1 \mathrm{pg} / \mathrm{mL}$ (38). This cytokine seems to be overexpressed not only in the sera of patients with AOSD, but also at tissue level, as higher levels of IL-18 were also described in synovial (39), lymph nodes (40) and liver (41).

Besides the potential role of diagnostic biomarker, IL-18 could also be an indicator of disease severity (42), as its serum levels are known to correlate with disease activity, hepatitis, ferritinemia and steroid dependence $(10,34,42,43)$. Moreover, an association between AOSD and IL-18 gene polymorphism has been described, giving credit to a specific role of this cytokine in the disease (44).

IL-18, mainly resulting from macrophage activation, seems to be higher in the serum of patients presenting with a systemic subset (when compared to the chronic articular subtype) $(11,18)$. This cytokine is also a hallmark of RHL, and its specific contribution to pathogenesis in both cases seems undisputable (45). Whether IL-18 is an efficient marker for remission and follow-up is still under debate, as contradictory results on its effective decrease after treatment have been reported $(38,43)$.

Hence, although dosages are not routinely performed, IL-18 could be a mechanistic biomarker useful for diagnosis, disease activity assessment, subset prediction and prognosis (Table 3).

$$
\text { 4.3.2. } I L-1 \beta
$$


IL-1 $\beta$ is a mechanistic biomarker, whose levels have been found elevated during AOSD, but not specific enough to be useful for diagnosis, because it cannot differentiate AOSD patients from subjects with sepsis $(21,35)$. However, it has been shown to correlate with disease activity (21) (Table 3).

\subsubsection{IL-6}

IL-6 is a mechanistic biomarker, whose levels have been found elevated during AOSD, but it is not specific enough to be useful for diagnosis, because it cannot differentiate AOSD patients from subjects with sepsis (21). The levels of IL-6, but not of TNF- $\alpha$, were shown to correlate with disease activity $(35,36)$ (Table 3).

\subsubsection{Cytokines as predictors of therapeutic response}

Data from literature suggest that different cytokine profiles may be responsible for distinct clinical manifestations, as systemic subsets seem to present with high levels of IL-18 and IL-1 $\beta$ (9), while patients with arthritis exhibit higher IL-6 serum levels (11). Similar results were found in sJIA, in a cohort comparing 33 AOSD with 77 sJIA (11).

As reported in section 3.4, the difference in AOSD subsets may have an impact on therapeutic responses $(7,9,10,25)$. However, cytokine dosages are not routinely performed and do not highlight our daily management of individual patients. They remain to be validated in further prospective studies comparing "systemic" AOSD with "rheumatic" AOSD patients, in order to help "monitoring" the disease (10). Furthermore, these "cytokine profiles" have not been clearly established. For instance, IL-6 serum levels are higher in patients with arthritis (11), but this cytokine has also been associated with severe systemic manifestations such as RHL (10).

\subsection{Proteins S100 A8/A9 and A12}

The S100 proteins represent the largest subgroup of calcium-binding protein. The most known are "calgranulins": S100A8 (calgranulin A), A9 (calgranulin B) and A12 (calgranulin C). S100A8 and A9 form heterocomplexes referred to as "calprotectin", while S100 A12 form homocomplexes (46). Calgranulins are released by activated phagocytes, mainly granulocytes, but also monocytes and macrophages, and represent one of the main pro-inflammatory mediators of the immune response, through Toll-Like Receptor (TLR)-4 activation (Figure 1) (46). Calgranulins possess numerous extracellular functions, such as 
chemotactic properties on neutrophils, monocytes or mast cells, triggering cell proliferation and generation of pro-inflammatory cytokines such as TNF- $\alpha$ and IL-1 $\beta$, activation of the microvascular endothelium, up-regulation of thrombogenic factors and an increase of junctional permeability (46). Massive release and interaction of calgranulins has been observed in vasculitis and inflammatory arthritis (46). A possible pathogenic role for S100 proteins over the course of AOSD and sJIA (Figure 1), but also of several autoinflammatory syndromes, such as Mediterranean fever or inflammatory bowel diseases has been hypothesized. In these conditions, a dysregulation of alternative secretory pathways leading to hypersecretion of calgranulins may be involved in disease pathogenesis $(12,46)$.

AOSD patients exhibit higher serum levels of calprotectin when compared to RA patients or healthy controls $(38,47,48)$. The levels of S100A8/A9 proteins correlate with disease activity and severity $(38,47,48)$. A positive correlation was found with leukocyte count, ESR, CRP, ferritin, TNF- $\alpha$, IL-1 $\beta$ and systemic disease scores $(38,47,48)$. The calprotectin levels also showed a decrease in treated patents, after disease activity status resolution (47). Of note, a calprotectin elevation can also be found in sera of patients with bacterial sepsis, and a study suggested that levels could not differentiate between microbial and intrinsic AOSD inflammation, although this should be tempered by the relatively small population studied (21).

S100A12 have shown to be an efficient marker for differentiating sJIA from other causes of fever of unknown origin (49), and for monitoring disease activity and response to therapies in the juvenile disease (50). In AOSD, a correlation with disease activity, serological markers (ESR, CRP, ferritin) and systemic score was described (51).

\subsection{Other potential biomarkers}

\subsubsection{Procalcitonin}

The usefulness of procalcitonin (PCT) as a biomarker for differential diagnosis in AOSD febrile patients could not be demonstrated. Indeed, an overexpression of this molecule can be detected even in the absence of infections in patients with AOSD. While the serum levels of PCT discriminating an infection have been identified as lower than $0.05 \mathrm{ng} / \mathrm{mL}$, Scirè et al. showed that $80 \%$ of patients with AOSD presented PCT serum levels higher than normal, even in the absence of infections (mean value $19.6 \mathrm{ng} / \mathrm{mL}$ ) (52). 


\subsubsection{AGEs and RAGE}

Accumulating evidence has demonstrated a pathogenic role of advanced glycation end products (AGEs) and receptors for AGEs (RAGE) in inflammation. AGEs serum levels are significantly higher (and conversely, soluble (s)RAGE are significantly lower) in active AOSD and active systemic lupus erythematosus than those in healthy controls (53). AGEs levels are positively (and conversely plasma sRAGE levels are negatively) correlated with AOSD activity scores, ferritin levels and CRP levels (53). In comparison to AOSD patients with monocyclic pattern, significantly higher AGEs serum levels are observed in AOSD patients with polycyclic or chronic articular patterns (53).

\subsubsection{CXCL10 and CXCL13}

C-X-C motif chemokine 10 (CXCL10) is produced in response to IFN- $\gamma$. CXCL13 is constitutively expressed in secondary lymphoid tissues, and the expression is upregulated by TNF- $\alpha$, via T cell stimulation. Both CXCL10 and CXCL13 levels were significantly higher in AOSD than in RA or healthy controls, and correlated with disease activity, ferritin and systemic scores (54).

\subsubsection{Markers reflecting macrophage activation and $R H L$}

The CD163 is a molecule expressed on cells of monocytic lineage, and is released by shedding into the sera, in the form of soluble sCD163, during macrophage activation (55). Such activation may be triggered by different stimuli, such as the binding of LPS on TLR4. High serum levels have been observed in patients with RHL (and is therefore considered as a key biomarker for such condition) $(12,56)$, but also during sepsis or liver pathologies (12). Recently, Colafrancesco et al. explored the utility of sCD163 as a diagnostic biomarker of AOSD in febrile patients. Although serum levels were significantly higher in AOSD patients than in healthy controls, no statistical differences were however found when compared to septic patients (57).

Macrophage inhibitory factor (MIF) serum levels are higher in AOSD than in patients with sepsis, RA, or malignancy, or healthy subjects, and correlate with disease activity (58).

Intracellular adhesion molecule-1 (ICAM1) serum levels are higher in AOSD than RA patients or healthy subjects, correlate with disease activity, and may predict hepatic dysfunction or disseminated intravascular coagulation (59). 


\section{Conclusion}

Although a number of publications describe potential biomarkers, very few were evaluated by more than one to three study groups. Therefore, there is a need to confirm and consolidate findings from discovery studies, and validate biomarkers for the assessment of diagnosis (i.e. markers able to rule out differential diagnoses), evolution, disease activity, severity and treatment efficacy. The use of emerging technologies, such as proteomics or metabolomics (60), with collaborative efforts, may ultimately help achieve the goal of validating new biomarkers (or a panel of biomarkers) for improving the management of AOSD. This might also be helpful in identifying new potential therapeutic targets.

\section{Conflicts of interest}

None of the authors has any conflicts of interest to declare.

\section{Appendix A. Supplementary data}

Supplementary data (table S1) associated with this article can be found in the online version at ... 


\section{References}

1. Bywaters EG. Still's disease in the adult. Ann Rheum Dis 1971;30(2):121-133.

2. Fautrel B. Adult-onset Still disease. Best Pract Res Clin Rheumatol. 2008; 22(5):773-92.

3. Gerfaud-Valentin M, Jamilloux Y, Iwaz J, Sève P. Adult-onset Still's disease. Autoimmun Rev. 2014; 13(7):708-22.

4. Yamaguchi M, Ohta A, Tsunematu T, Kasukawa R, Mizushima Y, Kashiwagi H, et al. Preliminary criteria criteria for classification of adult Still's disease. J Rheumatol 1992;19(3):42430.

5. Mert A, Ozaras R, Tabak F, Bilir M, Ozturk R, Ozdogan H, et al. Fever of unknown origin: a review of 20 patients with adult-onset Still's disease. Clin Rheumatol. 2003;22(2):89-93.

6. Gerfaud-Valentin M, Maucort-Boulch D, Hot A, Iwaz J, Ninet J, Durieu I et al. Adult-onset Stil disease: manifestations, treatments, outcome, and prognostic factors in 57 patients. Medicine (Baltimore) 2014; 93(2):91-9.

7. Kim HA, Sung JM, Suh CH. Therapeutic responses and prognosis in adult-onset Still's disease. Rheumatol Int 2012;32:1291-8.

8. Fautrel B, Zing E, Goldmard JL, Le Moel G, Bissery A, Rioux C, et al. Proposal for new set of classification criteria for adult-onset still disease. Medicine (Baltimore). 2002;81(3):194-200.

9. Jamilloux Y, Gerfaud-Valentin M, Martinon F, Belot A, Henry T, Sève P. Pathogenesis of adultonset Still's disease: new insights from the juvenile counterpart. Immunol Res. 2015 ;61(1-2):5362 .

10. Maria ATJ, Le Quellec A, Jorgensen C, Touitou I, Rivière S, Guilpain P. Adult onset Still's disease (AOSD) in the era of biologic therapies: Dichotomous view for cytokine and clinical expressions. Autoimmun Rev. 2014 ;13(11): 1149-59.

11. Inoue N, Shimizu M, Tsunoda S, Kawano M, Matsumura M, Yachie A. Cytokine profile in adultonset Still's disease: Comparison with systemic juvenile idiopathic arthritis. Clin Immunol. 2016 ;169:8-13.

12. Colafrancesco S, Priori R, Valesini G. Presentation and diagnosis of adult-onset Still's disease: the implications of current and emerging markers in overcoming the diagnostic challenge. Expert Rev Clin Immunol. 2015; 11(6):749-61.

13. Grateau G, Hentgen V, Stankovic Stojanovic K, Jéru I, Amselem S, Steichen O. How should we approach classification of autoinflammatory diseases? Nat Rev Rheumatol. 2013;9(10):624-9.

14. Peckham D, Scambler T, Savic S, McDermott MF. The burgeoning field of innate immunemediated disease and autoinflammation. J Pathol. 2017;241(2): 123-139.

15. Larroche C, Mouthon L. Pathogenesis of hemophagocytic syndrome (HPS). Autoimmun Rev. $2004 ; 3(2): 69-75$.

16. Robinson WH, Lindstrom TM, Cheung RK, Sokolove J. Mechanistic biomarkers for clinical decision making in rheumatic diseases. Nat Rev Rheumatol. 2013 ;9(5):267-76.

17. Gohar F, Kessel C, Lavric M, Holzinger D, Foell D. Review of biomarkers in systemic juvenile idiopathic arthritis: helpful tools or just playing tricks? Arthritis Res Ther. 2016 ;18:163. 
18. Ichida H, Kawaguchi Y, Sugiura T, Takagi K, Katsumata Y, Gono T, et al. Clinical manifestations of Adult-onset Still's disease presenting with erosive arthritis: Association with low levels of ferritin and Interleukin-18. Arthritis Care Res (Hoboken). 2014 ;66(4):642-6.

19. Shimizu M, Yokoyama T, Yamada K, Kaneda H, Wada H, Wada T, et al. Distinct cytokine profiles of systemic-onset juvenile idiopathic arthritis-associated macrophage activation syndrome with particular emphasis on the role of interleukin-18 in its pathogenesis. Rheumatology (Oxford). $2010 ; 49(9): 1645-53$.

20. Pouchot J, Sampalis JS, Beaudet F, Carette S, Décary F, Salusinsky-Sternbach M, et al. Adult Still's disease: manifestations, disease course, and outcome in 62 patients. Medicine (Baltimore). 1991;70(2):1118-36.

21. Rau M, Schiller M, Krienke S, Heyder P, Lorenz H, Blank N. Clinical manifestations but not cytokine profiles differentiate adult-onset Still's disease and sepsis. J Rheumatol. 2010 ;37(11):2369-76.

22. Piram M, Koné-Paut I, Lachmann HJ, Frenkel J, Ozen S, Kuemmerle-Deschner J, et al. Validation of the auto-inflammatory diseases activity index (AIDAI) for hereditary recurrent fever syndromes. Ann Rheum Dis. 2014;73(12):2168-73.

23. Efthimiou P, Kavadath S, Mehta B. Life-threatening complications of adult-onset Still's disease. Clin Rheumatol. 2014;33(3):305-14.

24. Ruscitti P, Cipriani P, Masedu F, Iacono D, Ciccia F, Liakouli V, et al. Adult-onset Still's disease: evaluation of prognostic tools and validation of the systemic score by analysis of 100 cases from three centers. BMC Med. 2016 ;14(1):194.

25. Gattorno M, Piccini A, Lasigliè D, Tassi S, Brisca G, Carta S, et al. The pattern of response to anti-interleukin-1 treatment distinguishes two subsets of patients with systemic-onset juvenile idiopathic arthritis. Arthritis Rheum. 2008;58:1505-15.

26. Ota T, Higashi S, Suzuki H, Eto S. Increased serum ferritin levels in adult Still's disease. Lancet. 1987; 1(8532):562-3.

27. Ohta A, Yamaguchi M, Tsunematsu T, Kasukawa R, Mizushima H, Kashiwagi H, et al. Adult Still's disease: a multicenter survey of Japanese patients. J Rheumatol. 1990 ;17(8):1058-63.

28. Fautrel B, Le Moël G, Saint-Marcoux B, Taupin P, Vignes S, Rozenberg S, et al. Diagnostic value of ferritin and glycosylated ferritin in adult-onset Still's disease. J Rheumatol. 2001; 28(2):322-9.

29. Lee MH, Means RT Jr. Extremely elevated serum ferritin levels in a university hospital: associated diseases and clinical significance. Am J Med. 1995; 98(6):566-71.

30. Colina M, Zucchini W, Ciancio G, Orzincolo C, Trotta F, Govoni M. The evolution of adult-onset Still disease: an observational and comparative study in a cohort of 76 Italian patients. Semin Arthritis Rheum. $2011 ; 41(2): 279-85$.

31. Rosário C, Zandman-Goddard G, Meyron-Holtz EG, D'Cruz DP, Shoenfeld Y. The hyperferritinemic syndrome: macrophage activation syndrome, Still's disease, septic shock and catastrophic antiphospholipid syndrome. BMC Med. 2013;11:185.

32. Van Reeth C, Le Moël G, Lasne Y, Revenant MC, Agneray J, Kahn MF, et al. Serum ferritin and isoferritins are tools for diagnosis of active adult Still's disease. J Rheumatol. 1994;21(5):890-5. 
33. Vigne S, Le Moël G, Fautrel B, Wechsler B, Godeau P, Piette JC. Percentage of glycosylated serum ferritin remains low throughout the course of adult onset Still's disease. Ann Rheum Dis. $2000 ; 59(5): 347-50$.

34. Kawashima M, Yamamura M, Taniani M, Yamauchi H, Tanimoto T, Kurimoto M, et al. Levels of interleukin-18 and its binding inhibitors in the blood circulation of patients with adult-onset Still's disease. Arthritis Rheum. 2001 ;44(3):550-60.

35. Choi JH, Suh CH, Lee YM, Suh YJ, Lee SK, Kim SS, et al. Serum cytokine profiles in patients with adult onset Still's disease. J Rheumatol. 2003;30(11):2422-7.

36. Chen DY, Lan JL, Lin FJ, Hsieh TY. Proinflammatory cytokine profiles in sera and pathological tissues of patients with active untreated adult onset Still's disease. J Rheumatol 2004;31(11):2189-98.

37. Priori R, Colafrancesco, Alessandri C, Minniti A, Perricone C, Iaiani G, et al. Interleukin 18: a biomarker for differential diagnosis between adult-onset Still's disease and sepsis. J Rheumatol. 2014;41(6):1118-23.

38. Kim HA, An JM, Nam JY, Jeon JY, Suh CH. Serum S100A8/A9, but not follistatin-like protein 1 and interleukin 18, may be a useful biomarker of disease activity in adult-onset Still's disease. $\mathrm{J}$ Rheumatol. $2012 ; 39(7): 1399-406$.

39. Rooney T, Murphy E, Benito M, Roux-Lombard P, Fitzgerald O, Dayer JM, et al. Synovial tissue interleukin-18 expression and the response to treatment in patients with inflammatory arthritis. Ann Rheum Dis. 2004;63(11):1393-8.

40. Conigliaro P, Priori P, Bombardieri M, Alessandri C, Barone F, Pitzalis C, et al. Lymph node IL18 expression in adult-onset Still's disease. Ann Rheum Dis. 2009;68(3):442-3.

41. Priori R, Barone F, Alessandri C, Colafrancesco S, McInness IB, Pitzalis C, et al. Markedly increased IL-18 liver expression in adult-onset Still's disease-related hepatitis. Rheumatology (Oxford). 2011;50(4):776-80.

42. Kawaguchi Y, Terajima H, Harigai M, Hara M, Kamatani N. Interleukin-18 as a novel diagnostic indicator of disease severity in adult-onset Still's disease. Arthritis Rheum. 2001 ;44(7):1716-7.

43. Jung KH, Kim JJ, Lee JS, Park W, Kim TH, Jun JB, Yoo DH. Interleukin-18 as an efficient marker for remission and follow-up in patients with inactive adult-onset Still's disease. Scand J Rheumatol. 2014;43(2):162-9.

44. Sugiura T, Kawaguchi Y, Harigai M, Terajima-Ichida H, Kitamura Y, Furuya T, el al. Association between adult-onset Still's disease and interleukin-18 gene polymorphisms. Genes Immun. 2002;3(7):394-9.

45. Maruyama J, Inokuma S. Cytokine profiles of macrophage activation syndrom associated with rheumatic diseases. J Rheumatol. 2010;37(5):967-73.

46. Foell D, Roth J. Proinflammatory S100 proteins in arthritis and autoimmune disease. Arthritis Rheum. 2004 ;50(12):3762-71.

47. Jung SY, Park YB, Ha YJ, Lee KH, Lee SK. Serum calprotectin as a marker for disease activity and severity in Adult-onset Still's disease. J Rheumatol. 2010 ;37(5):1029-1034. 
48. Kim HA, Han JH, Kim WJ, Noh HJ, An JM, Yim H, et al.TLR4 endogenous ligand S100A8/A9 levels in adult-onset Still's disease and their association with disease activity and clinical manifestatons. Int J Mol Sci. 2016 ;17(8). Pii: E1342.

49. Wittkowksi H, Frosch M, Wulffraat N, Goldbach-Mansky R, Kallinich T, Kuemmerle-Deschner $\mathrm{J}$, et al. S100A12 is a novel molecular marker differentiating systemic-onset juvenile idiopathic arthritis from other causes of fever of unknown origin. Arthritis Rheum. 2008;58(12):3924-31.

50. Foell D, Wittkowski H, Hammerschmidt I, Wulffraat N, Schmeling H, Frosch M, et al. Monitoring neutrophil activation in juvenile rheumatoid arthritis by S100A12 serum concentrations. Arthritis Rheum. 2004 ;50(4):1286-95.

51. Bae CB, Suh CH, An JM, Jung JY, Jeon JY, Nam JY, et al. Serum S100A12 may be a useful biomarker of disease activity in adult-onset Still's disease. J Rheumatol. 2014 ;41(12):2403-8.

52. Scirè CA, Cavagna L, Perotti C, Bruschi E, Caporali R, Montecucco C. Diagnostic value of procalcitonin measurement in febrile patients with systemic autoimmune diseases. Clin Exp Rheumatol. 2006;24(2):123-8.

53. Chen DY, Chen YM, Lin CC, Hsieh CW, Wu YC, Hung WT, et al. The potential role of advanced glycation end products (AGEs) and soluble recptors for AGEs (sRAGE) in the pathogenesis of adult-onset Still's disease. BMC Musculoskelet Disord. 2015 ;16:111.

54. Han JH, Suh CH, Jung JY, Nam JY, Kwon JE, Yim H, et al. Association of CXCL10 and CXCL13 levels with disease activity and cutaneous manifestation in active adult-onset Still's disease. Arthritis Res Ther. $2015 ; 17: 260$.

55. Møller HJ. Soluble CD163. Scand J Clin Lab Invest. 2012;72:1-13.

56. Bleesing J, Prada A, Siegel DM, Villanueva J, Olson J, Ilowite NT, et al. The diagnostic significance of soluble CD163 and soluble interleukin-2 receptor alpha-chain in macrophage activation syndrome and untreated new-onset juvenile idiopathic arthritis. Arthritis Rheum. 2007;56(3):965-71.

57. Colafrancesco S, Priori R, Alessandri C, Astorri E, Perricone C, Blank M, et al. sCD163 in AOSD: a biomarker for macrophage activation related to hyperferritinemia. Immunol Res. 2014;60(2-3):177-83.

58. Zou YQ, Lu LJ, Li SJ, Zeng T, Wang XD, Bao CD, et al. The levels of macrophage migration inhibitory factor as an indicator of disease activity and severity in adult-onset Still's disease. Clin Biochem. 2008 ;41(7-8):519-24.

59. Chen DY, Lan JL, Lin FJ, Ty H. Association of intercellular adhesion molecule-1 with clinical manifestations and interleukin-18 in patients with active, untreated adult-onset Still's disease. Arthritis Rheum. 2005 ;53(3):320-7.

60. Chen DY, Chen YM, Chien HJ, Lin CC, Hsieh CW, Chen HH, et al. Metabolic disturbances in adult-onset Still's disease evaluated using liquid chromatography/mass spectrometry-based metabolic analysis. Plos One. 2016 ;11(12):e0168147. 
Table 1. Main differential diagnoses of adult-onset Still's disease (not exhaustive) [adapted from $(2,3)]$

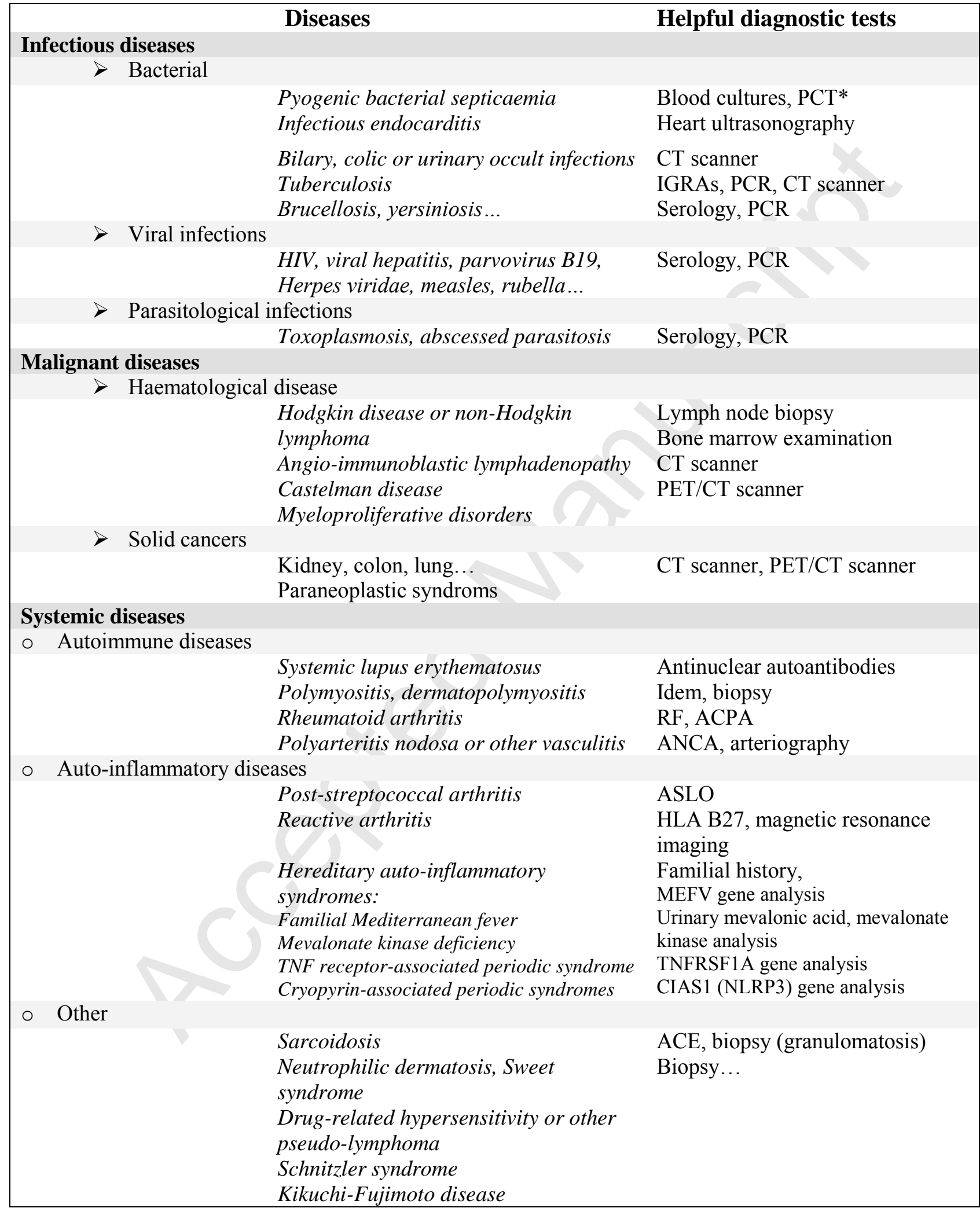

PCT, procalcitonin; CT, computed tomography; IGRAs, interferon gamma release assays; PCR, polymerase chain reaction; PET, positron emission tomography; RF, rheumatoid factor; ACPA, anti-citrullinated antibody; ANCA, anti-neutrophil cytoplasmic antibodies; ASLO, anti-streptolysin O antibody; HLA, human leukocyte antigen; MEFV, Mediterranean fever; TNFRS1A, tumour necrosis factor receptor superfamily member 1A; $\mathrm{ACE}$, angiotensin converting enzyme. 
Table 2: Classification criteria for adult-onset Still's disease.

\begin{tabular}{|c|c|}
\hline Yamaguchi et al. (4) & Fautrel et al. (8) \\
\hline \multicolumn{2}{|l|}{ Major criteria } \\
\hline 1. Fever $\geq 39^{\circ} \mathrm{C}$ lasting 1 week or more & 1. Spiking fever $\geq 39^{\circ} \mathrm{C}$ \\
\hline 2. Arthralgia lasting 2 weeks or more & 2. Arthralgia \\
\hline 3. Typical skin rash: maculopapular, non- & 3. Transient erythema \\
\hline pruritic, salmon-pink rash with & 4. Pharyngitis \\
\hline $\begin{array}{l}\text { concomitant fever spikes } \\
\text { 4. Leukocytosis }>10,000 / \mathrm{mm}^{3} \text { with }\end{array}$ & 5. Neutrophil polymorphonuclear count \\
\hline $\begin{array}{l}\text { neutrophil polymorphonuclear count } \geq \\
80 \%\end{array}$ & 6. Glycosylated ferritin fraction $\leq 20 \%$ \\
\hline \multicolumn{2}{|l|}{ Minor criteria } \\
\hline 1. Pharyngitis or sore throat & 1. Typical rash \\
\hline 2. Lymphadenopathy and/or splenomegaly & 2. Leukocytosis $\geq 10,000 / \mathrm{mm}^{3}$ \\
\hline $\begin{array}{l}\text { 3. Liver enzyme abnormalities } \\
\text { (aminotransferases) }\end{array}$ & \\
\hline $\begin{array}{l}\text { 4. Negative for rheumatoid factor or } \\
\text { antinuclear antibodies }\end{array}$ & \\
\hline \multicolumn{2}{|l|}{ Exclusion criteria } \\
\hline $\begin{array}{l}\text { 1. Absence of infection, especially sepsis } \\
\text { and Epstein-Barr viral infection }\end{array}$ & None \\
\hline 2. Absence of malignant diseases, & \\
\hline $\begin{array}{l}\text { especially lymphomas } \\
\text { 3. Absence of inflammatory disease, }\end{array}$ & \\
\hline $\begin{array}{l}\text { 3. Absence of inflammatory disease, } \\
\text { especially polyarteritis nodosa }\end{array}$ & \\
\hline \multicolumn{2}{|l|}{ Diagnostic requires: } \\
\hline $\begin{array}{c}\text { At least } 5 \text { criteria, including } 2 \text { major criteria } \\
\text { and }\end{array}$ & major criteria \\
\hline No exclusion criteria & 3 major and 2 minor criteria \\
\hline
\end{tabular}

Yamaguchi's criteria have the best sensitivity of $96.2 \%$, and a specificity of $92.1 \%$. They are the most widely cited criteria in the literature, and the most widely validated. Nevertheless, they require the exclusion of neoplasms, infections and autoimmune diseases that mimic AOSD.

Using a 2002 retrospective analysis of 72 patients with AOSD and 130 controls, Fautrel et al. developed updated criteria with a sensitivity of $80.6 \%$, but a higher specificity of $98.5 \%$. These criteria do not require exclusions but include the glycosylated ferritin. 


\section{Table 3. Most relevant serum biomarkers identified to date through AOSD cohorts, and their indented potential use [adapted from $(12,17)]$.}

\begin{tabular}{|c|c|c|c|c|c|c|c|}
\hline \multicolumn{8}{|c|}{ Potential indented use } \\
\hline Biomarker & $\begin{array}{l}\text { Property } \\
\text { (Proxy/ } \\
\text { Mechanistic) }\end{array}$ & Diagnosis $^{1}$ & $\begin{array}{c}\text { Evolution }^{2} \\
\text { (Ss, systemic subset } \\
\text { As, arthritis subset) }\end{array}$ & $\begin{array}{c}\text { Disease } \\
\text { activity } \\
\text { assessment }\end{array}$ & $\begin{array}{c}\text { Severity } \\
\text { assessment } \\
\text { (Life-threatening } \\
\text { complications } \\
\text { prediction) } \\
\end{array}$ & $\begin{array}{c}\text { Monitoring } \\
\text { (decrease } \\
\text { after } \\
\text { treatment) }\end{array}$ & Ref \\
\hline CRP & $\mathrm{P}$ & - & - & + & - & + & - \\
\hline SAA & $\mathrm{P}$ & NA & NA & NA & $\begin{array}{c}+ \\
\text { Predictive of AA } \\
\text { amyloidosis }\end{array}$ & NA & - \\
\hline Ferritin & $\begin{array}{c}\mathrm{P} \\
\text { (M?) }\end{array}$ & $\begin{array}{c}++ \\
\text { Se } 40.8 \% \text { and Spe } 80 \% \text { if } \\
\geq 5 \mathrm{~N} \\
(\geq 1000 \mu \mathrm{g} / \mathrm{L})\end{array}$ & $\begin{array}{c}+/- \\
\text { High levels seem } \\
\text { associated with } \mathrm{Ss}^{3}\end{array}$ & + & + & + & $(26-31)$ \\
\hline $\begin{array}{l}\text { Glycosylated } \\
\text { ferritin (GF) }\end{array}$ & $\mathrm{M}$ ? & $\begin{array}{c}+ \\
\text { Se } 79.5 \% \text { and Spe } 66.4 \% \text { if } \\
G F \leq 20 \%\end{array}$ & NA & - & $\begin{array}{c}+ \\
G F \leq 20 \% \text { is } \\
\text { associated to } \\
\text { RHL }\end{array}$ & - & $(26-33)$ \\
\hline $\begin{array}{l}\text { Combination } \\
\text { Ferritin and GF }\end{array}$ & $\mathrm{P}$ & $\begin{array}{c}++ \\
\text { Se } 70.5 \% \text { and Spe } 83.2 \% \\
(\text { Spe } 92.9 \% \text { ifferritin }>5 N)\end{array}$ & - & - & - & - & $(26-33)$ \\
\hline Interleukin-18 & $\mathrm{M}$ & $\begin{array}{c}+ \\
\text { Cut-off for distinguishing } \\
\text { from sepsis: } \\
148.9 \mathrm{pg} / \mathrm{mL}=\text { Se } 88 \% \\
\text { Spe } 78 \% \\
\\
\text { 366.1 pg/mL }=\text { Se } 91.7 \% \\
\text { Spe } 99.1 \% \\
\end{array}$ & $\begin{array}{c}++ \\
\text { High levels seem } \\
\text { associated with Ss }\end{array}$ & + & $\begin{array}{c}+ \\
\text { High levels are } \\
\text { associated with } \\
\text { RH, hepatitis and } \\
\text { steroid } \\
\text { dependence }\end{array}$ & NA & $(34-45)$ \\
\hline Interleukin-1 $\beta$ & $\mathrm{M}$ & ${ }^{5}$ & $\begin{array}{c}+/- \\
\text { High levels seem } \\
\text { associated with Ss }\end{array}$ & + & $+/-$ & NA & $(21,35,36)$ \\
\hline Interleukin-6 & $\mathrm{M}$ & $-^{5}$ & $\begin{array}{c}+/- \\
\text { High levels seem } \\
\text { associated with As }\end{array}$ & + & $\begin{array}{c}+/- \\
\text { High levels are } \\
\text { associated with } \\
\text { RHL } \\
\end{array}$ & NA & $(35,36)$ \\
\hline TNF- $\alpha$ & $\mathrm{M}$ & $\begin{array}{l}5 \\
-\end{array}$ & - & - & - & NA & $(35,36)$ \\
\hline $\begin{array}{l}\text { Calprotectin } \\
\text { (S100A8/A9 } \\
\text { proteins) }\end{array}$ & $\mathrm{M}$ & $+-^{6}$ & NA & + & NA & + & $(38,47,48)$ \\
\hline $\begin{array}{l}\text { S100A12 } \\
\text { protein }\end{array}$ & $\mathrm{M}$ & 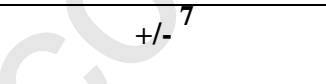 & NA & + & NA & $+/_{-}{ }^{7}$ & $(49-51)$ \\
\hline Procalcitonin & $\mathrm{M}$ & 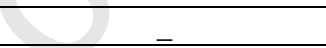 & $\mathrm{NA}$ & NA & NA & NA & $(52)$ \\
\hline $\begin{array}{l}\text { AGEs and } \\
\text { sRAGE }\end{array}$ & $\mathrm{M}$ & $y$ & $\begin{array}{c}+ \\
\text { Higher AGEs in serum } \\
\text { of polycyclic or } \\
\text { chronic articular } \\
\text { patterns (compared to } \\
\text { monocyclic) } \\
\end{array}$ & + & NA & + & (53) \\
\hline CXCL10 & $\mathrm{M}$ & + & NA & + & NA & NA & $(54)$ \\
\hline CXCL13 & $\mathrm{M}$ & + & NA & + & NA & NA & (54) \\
\hline sCD163 & $\mathrm{M}$ & $+/-$ & NA & NA & NA & NA & $(56,57)$ \\
\hline MIF & $\mathrm{M}$ & + & NA & + & NA & NA & (58) \\
\hline ICAM1 & $\mathrm{M}$ & $+/-$ & NA & + & NA & NA & (59) \\
\hline
\end{tabular}

+, yes; -, no; +/-, tested, but contradictory results: need for more studies to draw a conclusive opinion; NA, not assessed so far. "Proxy" markers are consequences of the pathogenic process, while "mechanistic" biomarkers are directly involved in pathogenic mechanism. ${ }^{1} \mathrm{~A}$ good diagnostic biomarker helps to rule out the differential diagnoses of infection, malignancy and other inflammatory 
disorders. ${ }^{2}$ Identifying the diseases subset might orientate the therapeutic strategy. ${ }^{3}$ Serum ferritin levels are significantly higher in the systemic subtype (18), but high ferritin levels after adequate treatment may be a predictor of chronic articular course (30). ${ }^{4}$ Regardless of whether the cause of RHL is AOSD-related, infectious, neoplastic or inflammatory. ${ }^{5}$ Elevated plasma levels of IL- $1 \beta$, IL-6 and TNF- $\alpha$ have been found during AOSD, but the cytokine profile is not specific and cannot differentiate AOSD patients from subjects with sepsis. ${ }^{6}$ Calprotectin levels help to rule out rheumatoid arthritis, but further studies are necessary to validate it as a diagnostic biomarker, because there was no statistical difference between AOSD and septic patients, although the population were small (25). ${ }^{7}$ S100A12 have shown to be an efficient diagnostic and monitoring biomarker in Systemic Juvenile Arthritis (sJIA), but further studies are needed to validate them in AOSD.

CRP, C-reactive protein; SAA, serum amyloid A protein; AA amyloidosis, amyloid A amyloidosis; RHL, reactive haemophagocytic lymphohistiocytosis; TNF- $\alpha$, tumour necrosis factor- $\alpha$; MIF, macrophage inhibitory factor; ICAM1, Intracellular adhesion molecule-1 (ICAM1); AGEs, advanced glycation end products (AGEs), sRAGE, soluble receptors for AGEs. 
Figure 1. Simplified proposed pathophysiological model for adult-onset Still's disease [adapted from $(2,3,10)]$.

Environmental trigger (pathogen-associated or damage-associated molecular patterns, PAMPs or DAMPs) set fire to a dysregulated NLRP3 inflammasome, mainly in monocytes, resulting in enhanced caspase- 1 activation. In turn, caspase- 1 cleaves inactive pro-IL-1 $\beta$ and pro-IL-18 into mature IL-1 $\beta$ and IL-18, which are the secreted active forms. Binding of IL-1 $\beta$ and IL-18 to their receptors activate $\mathrm{NF \kappa B}$, a transcription factor that governs the expression of the proinflammatory cytokine genes. This leads to an increased production of pro-inflammatory cytokine (IL-1 $\beta$, IL-6, IL-8, TNF- $\alpha$, IL-18, IFN- $\gamma$ ), responsible for the main clinical and biological features of the disease. Unrestrained macrophage activation can sometimes lead to uncontrolled haemophagocytosis and reactive haemophagocytic lymphohistiocytosis (RHL). Neutrophils and monocytes express highly increased amounts of S100 proteins. S100A8 and S100A9 form heterocomplexes referred to as "calprotectin", while S100 A12 form homocomplexes. These S100 proteins (or calgranulins) act in tun as DAMPs or "alarmins", which act as substrates for innate-immunity receptors, such as Toll-Like Receptors (TLR)-4 or receptors for advanced glycation end products (RAGE). TLR and RAGE pathways in monocytes/macrophages activate $\mathrm{NF \kappa B}$, contributing to the aforementioned expression of pro-inflammatory cytokines.

Figure 2. Biomarker need in clinical context [adapted from $(16,17)$ ]: typical clinical sequence in adult-onset Still's disease (AOSD) from disease onset, diagnosis to clinical resolution and flare. Specific time points where there is a need for diagnostic and prognostic biomarkers are indicated. Diagnostic biomarkers are indicated as follows: D1 AOSD versus non-AOSD conditions (i.e. infections, malignancies, and other inflammatory conditions), D2 disease evolution (i.e. systemic or chronic articular). Prognostic markers are indicated as follows: P1 prognostic for increased disease activity and flare, P2 severity assessment and prediction of an unfavourable outcome, P3 treatment monitoring and prediction of the therapeutic response.

\section{Figure 3. Schematic representation of the possible evolution patterns in AOSD.}

Historically, the clinical course of AOSD has been distinguished in three different patterns, described on the basis of the evolution of symptoms over time (2). The monocyclic pattern $(19-44 \%)$ is a systemic form of AOSD, usually self-limited, with disease limited to a single flare and complete remission achieved within a couple of weeks or months. The polycyclic 
pattern $(10-41 \%)$ is characterized by the recurrence of systemic or articular flares separated by periods of remission lasting from a couple of weeks to a couple of years. Differently from the others, the chronic evolution (35-67\%) is more frequently articular than systemic, and one-third of these patients develop erosive arthritis (2).

In light of the new pieces of evidence about AOSD pathogenesis and treatment, many authors have now adopted a new dichotomous classification, distinguishing two AOSD subtypes according to dominant clinical evolution: a systemic subtype, including patients with systemic features (such as high fever and skin rash), more at risk to develop life-threatening complications (such as multi-organ involvement), and RHL, and a subtype where patients have predominant articular involvement. 
Virus

\section{Parasite}

Bacteria
Genetic

predisposition?

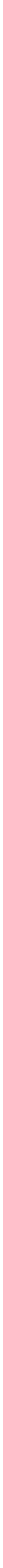




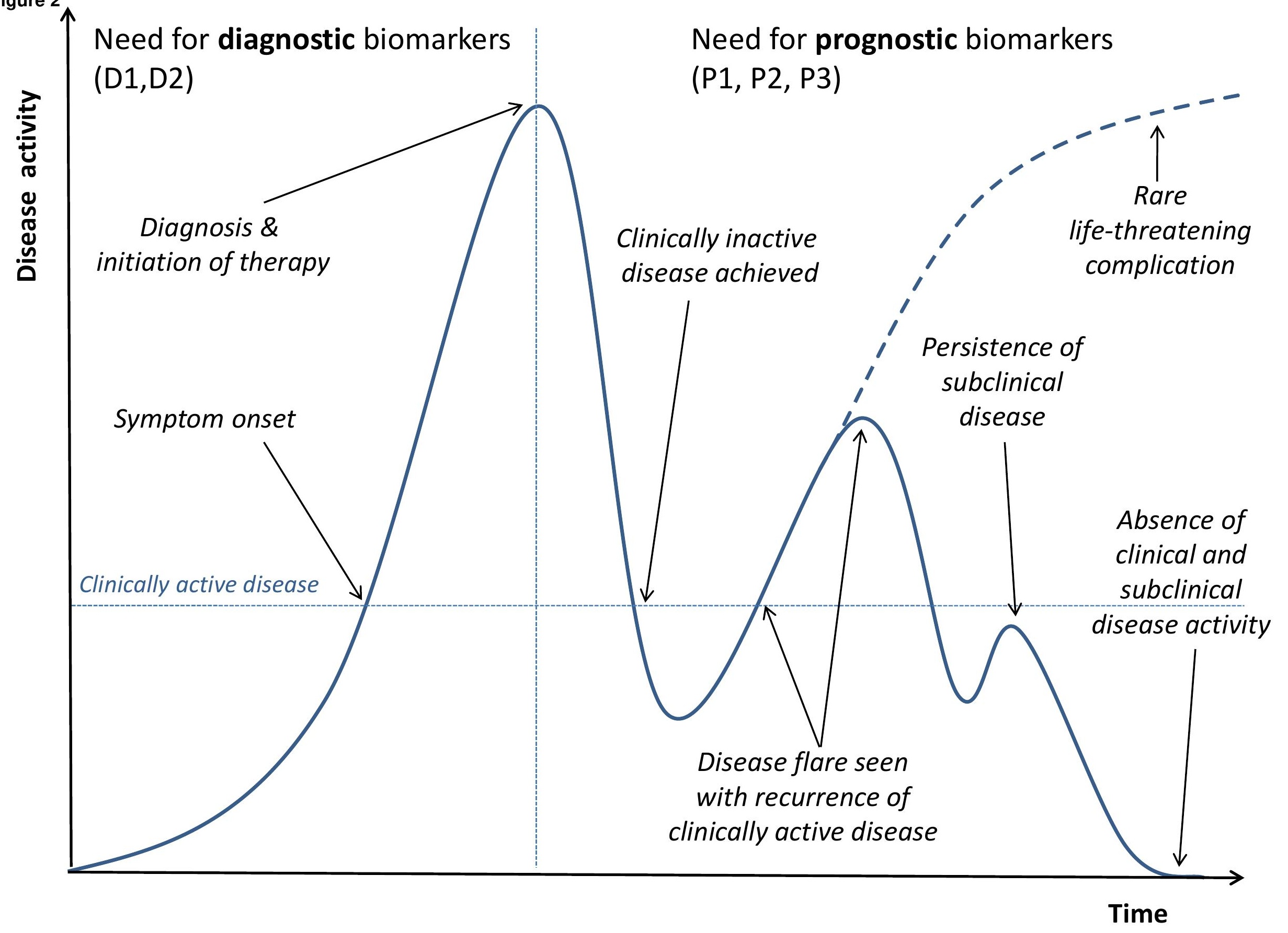




\section{Systemic subtype}

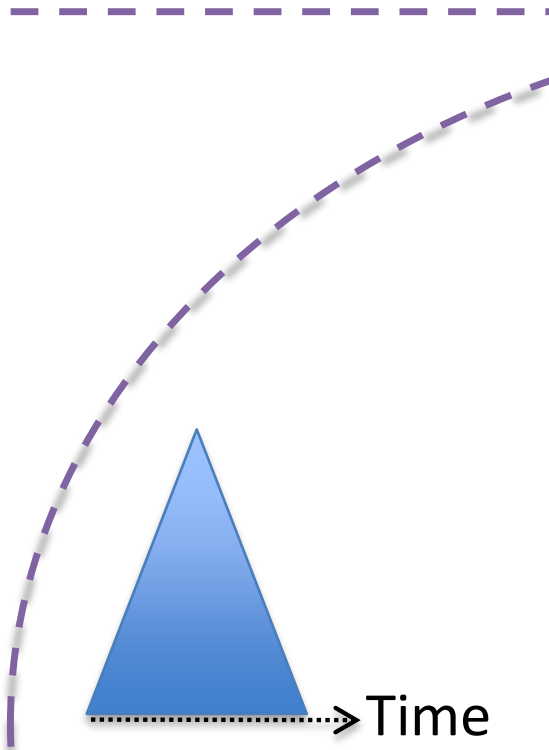
Monocyclic

\section{Arthritis subtype}

(n)
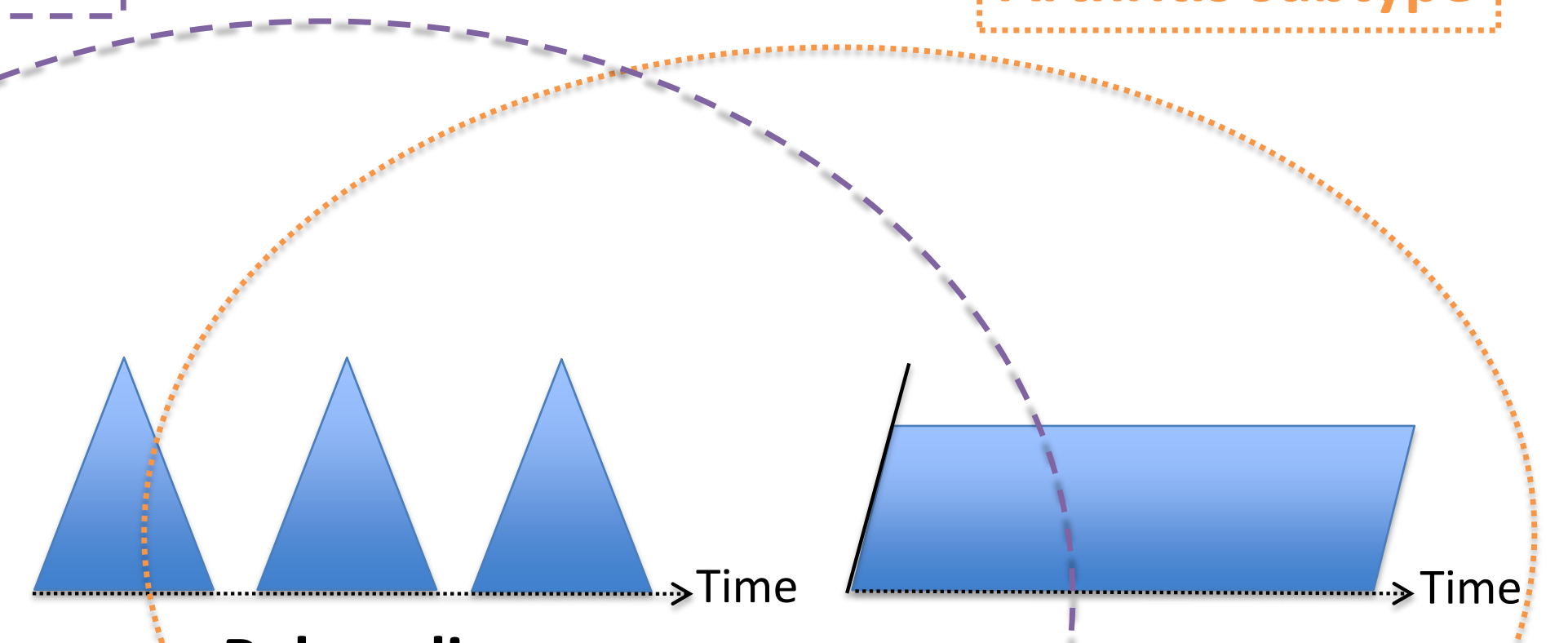

Polycyclic

Chronic continuous

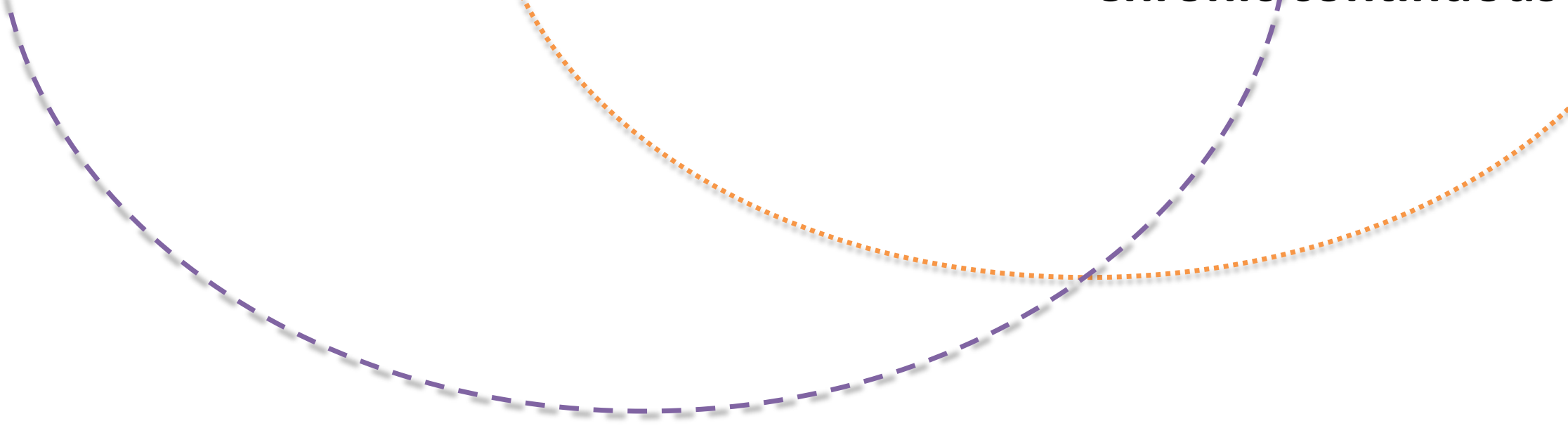

